\title{
Analysis on Great Wall Motor Sales Logistics Model and Design of Hub and Spoke Network
}

\author{
Hua Li Zhengfa Yang \\ Institute of Economic and Trade, Jiangxi University of Technology, Nanchang 330098, China
}

Keywords: Automotive Logistics; Sales Logistics; Self Logistics; Hub and Spoke Network

\begin{abstract}
In recent years, the rapid development of China's automobile ind ustry has led to the rapid booming development of China's automotive logistics industry. As competition intensifies, car manufacturers have attached more and more attention to logistics management, and their internal desire to modernized operation also becomes more and more urgent, which requires car manufacturers to take a series of measures, so as to increase the size, network and service of the logistics operation, and expand the scope of services and capabilities of logistics operations. Meanwhile, in order to meet the needs of the automotive industry, to improve the logistics efficiency of China's automobile manufacturing industry, researchers China should develop a vehicle sales logistics mode that is appropriate to the national conditions, and design a rational logistics network model.
\end{abstract}

\section{Introduction}

Automotive logistics industry has been deemed as the most complex and the most professional field in the logistics industry. Logistics development in China is relatively backward relative to developed countries, and thus the understanding of the automotive logistics is relatively scarce. At present, China's auto logistics base is weak, the market is obviously divided, and there is a lack of industry standards, adding to the single competition means...all these is sues have seriously hampere the growth of China's automotive logistics efficiency, and restricted business efficiency growth. However, with growing economy in China, and competitions in the automotive market, the automotive industry is facing the pressures from fierce global competition, lower prices and increasingly lean production, etc.; more and more enterprises begin to focus on the New World of the logistics, striving to improve vehicle logistics efficiency, in order to increase the fundamental benefits and core competitiveness of the business.

In particular those leading automobile manufacturers in the ind ustry, their vehicle sales volume is relatively large. Their vehicle sales and distribution network is located throughout the country, so the construction of a sound vehicle sales and distribution network is of great significance..

\section{Status and problems analysis of logistics models and vehicle sales in Great Wall Motor}

Situation of vehicle sales logistics models in Great Wall Motor. Existing logistics model of Great Wall Motor vehicle sales is self-logistics mode, and it is basically completed through Ants Logistics Company under Great Wall. The Great Wall has huge vehicle production, and has some inventory centers in various cities instead of storing all the vehicles in the production base. When the dealer places orders, vehicle manufacturers notify the dealer to get the vehicle at the nearest inventory center. This business investment of this model is large, but the speed of delivery is also faster, which is suitable for a mature vehicle manufacturers.

Current development status of logistics company under Great Wall Motor is still mainly providing transportation, warehousing and other functional logistics services, i.e. through price competition and functional services to join market competition. To change this situation, an important aspect is to go 
beyond the traditional model of logistics services, and innovate in the service concept, service content and service methods.

Proble ms analysis of logistics models in Great Wall Motor vehicle sales. Although Great Wall Motor's logistics market has a certain market scale, capable of regional distribution and cross-regional distribution, there are still some inevitable shortcomings, mainly in the following two aspects:

Insufficient technical support:

The Information System of Great Wall Motor's logistics is still not perfect, modernization level of logistics facilities is not high enough, work efficiency is not ideal, the overall technology is lagging behind, all contribute to the failure in providing a strong technical support for the distribution development.

Bottlenecks in management:

Logistics enterprise of Great Wall Motor doesn't have the modern logistics management professionals in vehicle distribution; as for the management method, there are problems of manual operation and experience-oriented decision-making; also, there are misallocation resources of management; in the management system, there are problems of industry segmentation, sector segmentation, and market segmentation. These management bottlenecks will severely restrict the innovation and development of the Great Wall Motor logistics distribution center, and affect the continuing process of profit creation.

\section{Hub and spoke logistics network design of Great Wall Motor vehicle sales}

Establishment of hub nodes. Principal component analysis, also known as principal component analysis, is designed to take advantage of lower-dimensional thinking, transferring more indicators into a few comprehensive indexes. The author used SPSS statistical software and selected the principal component analysis method to calculate the number of the vehicle needs and logistics service capacity score among100 administrative regions of the country, and made descending order for the results: the higher score is, the greater and stronger urban vehicle demand and logistics service capacity are. Among them, Beijing, Shanghai, Qingdao and other cities have higher score; they are near the port cities of Tianjin, Wuhu, and Dalian respectively, hence are not selected as the hub nodes. After comprehensive consideration, 23 cities:Tianjin, Dalian, Xi'an, Wuhu, Taiyuan, Harbin, Chengdu, Changsha, Kunming, Hohhot, Nanchang, Urumqi, Lhasa,, Wenzhou, Xiamen, Guangzhou, Fangcheng, Haikou, Yinchuan, Zhengzhou, Lanzhou, Chongqing Wuhan are finalized as hub and spoke logistics network nodes of the Great Wall sales .

Determination spatial level of vehicle sales logistics network hub node. Although the above mentioned 23 cities are hub nodes, there are still differences between the number of vehicle demand and service capacity per node, so researchers need to plan their spatial level. The concrete steps are as follows: collect traffic data of 23 hub nodes, use Dijkstra algorithm to analyze vehicle sales logistics transport method of Tianjin other 22 nodes, and then compare their economic advantages to determine the spatial level of logistics hub nodes.

Finalized vehicle sales logistics network hub node space level of Great Wall is as shown in Table 2 below:

Table 1 Space level of vehicle sales logistics hub nodes

\begin{tabular}{l|l|l}
\hline $\begin{array}{l}\text { Modes of } \\
\text { transport }\end{array}$ & hub nodes & $\begin{array}{l}\text { Space level of hub } \\
\text { nodes }\end{array}$ \\
\hline $\begin{array}{l}\text { Road } \\
\text { transport }\end{array}$ & Tianjin & Central hub \\
\hline Waterway & Dalian, Chongqing, Wuhan, Wuhu & Mixed hub \\
\hline
\end{tabular}




\begin{tabular}{l|l|l}
\hline transport & $\begin{array}{l}\text { Xiamen, Guangzhou, Wenzhou, Fangchenggang, } \\
\text { Haikou }\end{array}$ & Regional hub \\
\hline $\begin{array}{l}\text { Railway } \\
\text { transport }\end{array}$ & $\begin{array}{l}\text { Lanzhou, Nanchang, Urumqi, Lhasa, Xi'an, } \\
\text { Yinchuan, Zhengzhou, Taiyuan, Hohhot }\end{array}$ & Regional hub \\
\hline $\begin{array}{l}\text { Water and } \\
\text { railway } \\
\text { transport }\end{array}$ & $\begin{array}{l}\text { Harbin (Dalian transit), Chengdu (Chongqing } \\
\text { transit), Changsha (Wuhan transit), Kunming } \\
\text { (Chongqing transit) }\end{array}$ & Regional hub \\
\hline
\end{tabular}

Construction of hub and spoke logistics network. Construction of trunk network. As the core of the logistics network, the trunk is transport place of the main volume, the transport route between the hub nodes. The trunk network is divided into three levels:

(1) Main trunk: the central hub node - the transport routes formed by Tianjin and inter-mixed hub nodes, characterized by high demand, and the use of large capability of water transport.

(2) Trunk: central hub node - the transport routes formed by Tianjin and regional hub nodes. It could be divided two categories in terms of transport mode: one is the use of rail transport,; and another is the use of water transport;

(3) General trunk: the transport routes formed by mixing hub nodes and regional hub nodes; the transport volume of this type is low relative to the above two, and it uses rail transport mode.

Specifically as shown in Fig. 4 and Table

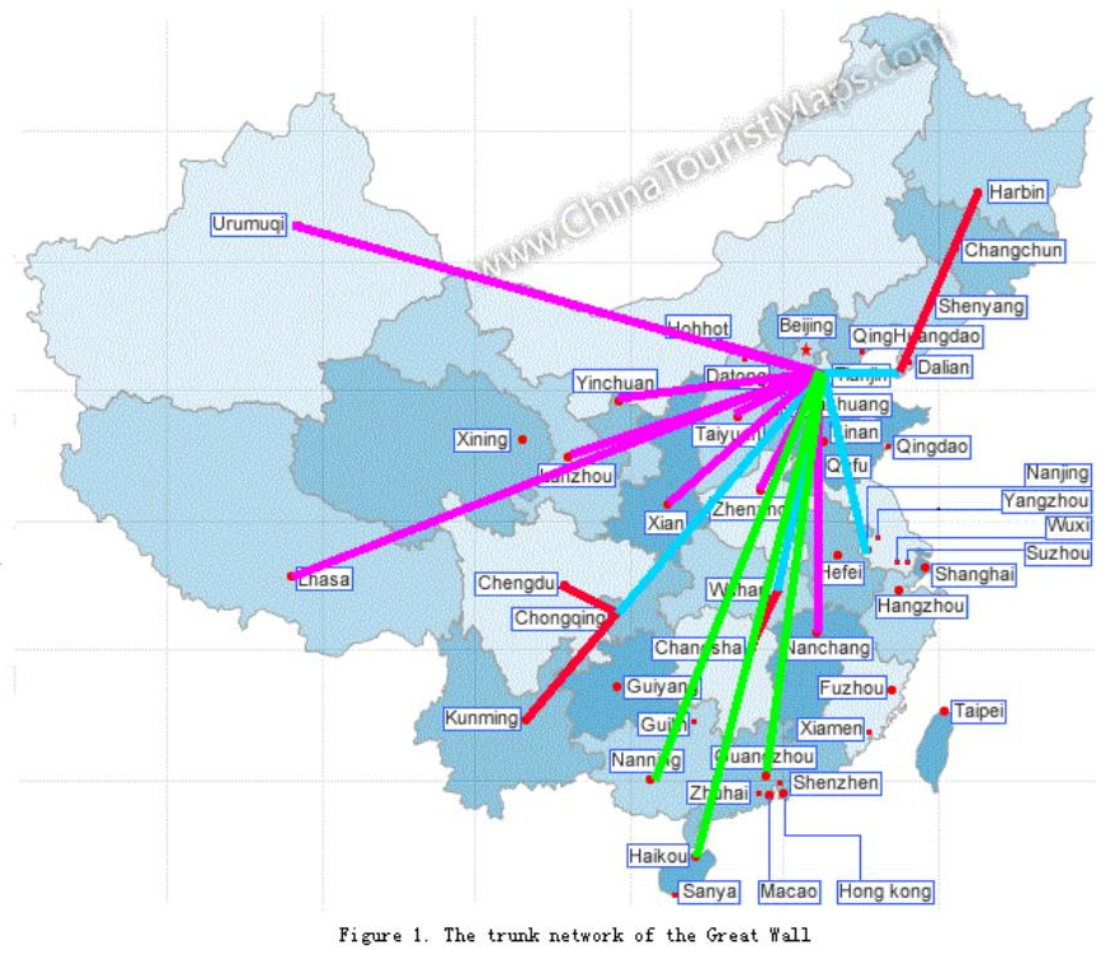

Fig. 1 Trunk netw ork of Great Wall Motor

Among them, the blue transport routes are main trunk main with water transport; Pink transport routes are trunk, with rail transport; green transport routes are trunk with water transport; red routes are the general trunk.

Construction of branch network: 
Branch network is fundamental to build Great Wall Motor vehicle sales hub and spoke logistics network, is the main support of hub nodes and trunk transport. In this paper, under ideal conditions, the construction of regional networks will follow the principle of proximity, principle of high proximity, and convenient road transport principle. See Fig. 2 and Table 1 below:

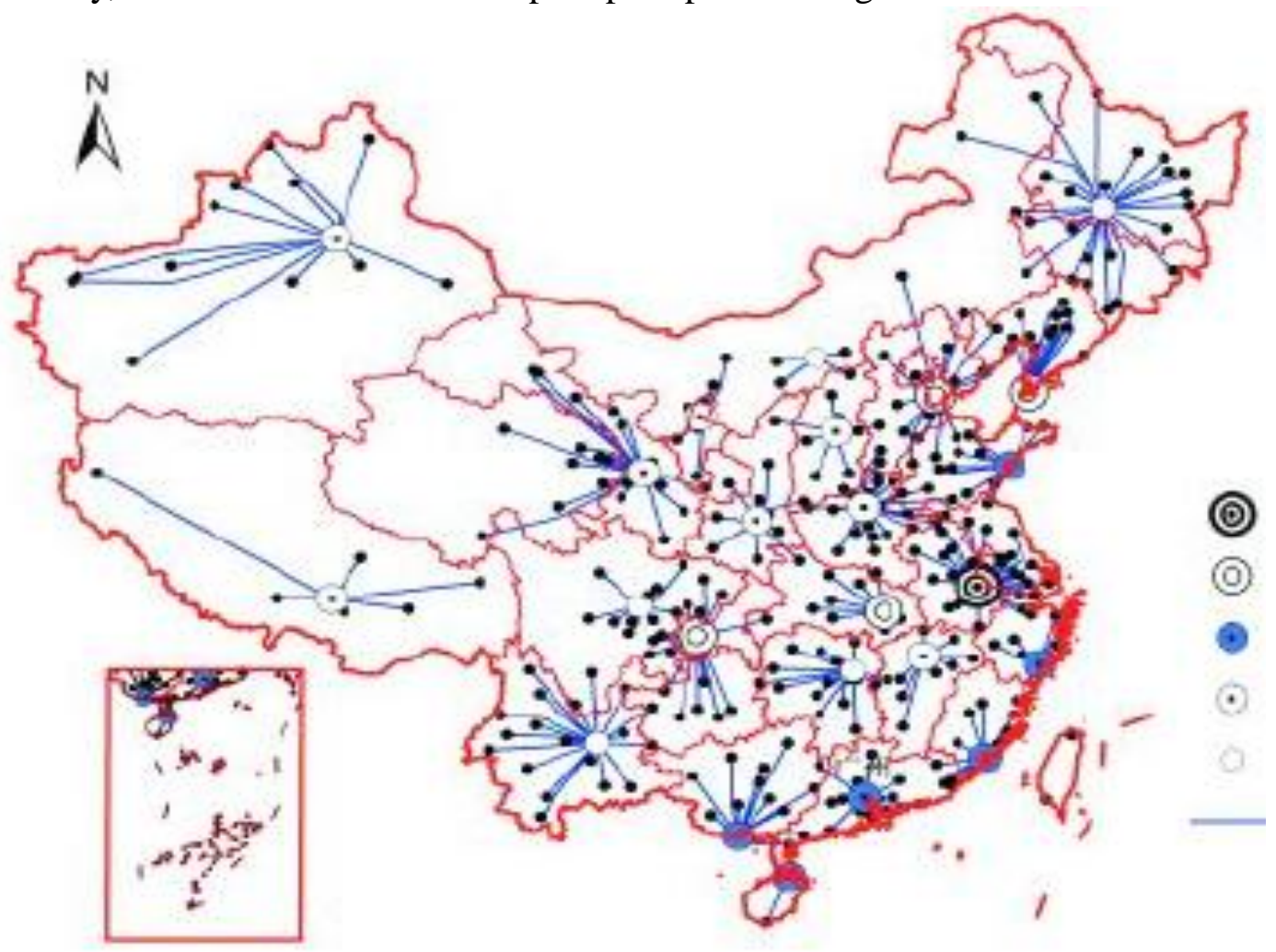

Great Wall Motor hub and spoke network branch network. According to interview materials, until 2013, Great Wall Motor in the country has a total of 14 interim libraries (the equivalent of the hub nodes). In the vehicle sales logistics hub and spoke network built by the paper, there are some adjustments in the position of some interim libraries, and the modes of transport have also changed.

According to Great Wall Motor vehicle sales data in 2013, the proportion of waterways, railways, road transport of vehicles were $10.18 \%, 76.52 \%$ and $6.51 \%$ (except direct selling vehicles and export vehicles).

It can be concluded, with respect to the original vehicle sales logistics network, hub and spoke logistics network method has dramatically increased the proportion of railway transport and water transport, especially water transport, which is expanded along the Yangtze River and the eastern coastal areas.

According to the knowledge learned, and generally speaking, if a logistics network is redesigned, researchers should decrease costs by $5 \%$ to $10 \%$ while meeting the current level of customer service provided. Thus, the Great Wall Motor vehicle sales logistics hub and spoke network built by the paper is superior to the original logistics network, which has saved the manpower, material resources, and financial resources, so as to improve transport efficiency and enhance the competitiveness of enterprises.

\section{Conclusions}

Chinese automotive logistics market is increasingly attracting the attention from many foreign companies, and the future competition of China's automotive logistics is bound to become increasingly intense; in order to accelerate the logistics development of vehicle sales in China, researchers should integrate vehicle sales logistics resources of auto manufacturers, improve level of service, change the backward state of service; accelerate the development of China's automotive 
logistics industry standards; specify internal competition, establish an effective price system; train logistics management personnel, and improve the logistics management.

Whether manufacturing companies choose self-logistics or third-party logistics, it is based on the comprehensive analysis from various aspects, such as core competitiveness of companies, self logistics management capabilities, management level, logistics costs, competitors and the development of national or regional logistics industry, etc.

\section{Acknowledgements}

This work was financially supported by The research result of the key construction disciplines, Industry Economics in Jiangxi University of Technology

\section{References}

[1] Xu Yongge, Chen Wenxia. Automobile logistics infrastructure [M]. Machinery Industry Press, 2006.1

[2] Wang Lei, Chen Huanjiang, Li Mao. Domestic automobile logistics development strategy [J] Logistics Technology, 2008, 31 (7): 4-6.

[3] Chen Feiping. Logistics mode selection and simulation of collaborative automobile manufacturers inbound on the supply chain [D]. Chongqing University, 2010.

[4] Zhao Changdong, Chen Hao. Study of China's automobile manufacturing enterprise logistics mode [J] Transport Standardization, 2007, 5: 144-146.

[5] Li Yang. Hub and spoke network theory and application of [D]. Fudan University, 2006.

[6] Li Haijian. "Hub and spoke" model research of Anhui regional logistics systems [D]. Anhui Normal University, Master's Degree Thesis, 2004.

[7] Wu Qitao, Zhang Hongou, Chen Fenggui, etc. Hub and spoke network model and its application in traffic geography [J] Advances in Geographic Sciences, 2010, 29 (6): 701-708.

[8] Wu Lina. Research of hub and spoke logistics system establishment. [J] Chinese Market, 2008, 6: 014.

[9] Xu Jian, Cao Youhui, Sun Wei. Hub and spoke logistics network construction of Yangtze River Delta based on road transport costs.[J] Geography Research, 2009, 28 (4): 911-919.

[10] Zhang Jian, Li Lin, Huhong Chun. Fast freight hub and spoke network research [J] Logistics Technology, 2008, 27 (1): 25-27. 